\title{
Prevalence of Lungworm Infection of Small Ruminants in and Around Bahir Dar City, Amhara Regional State, Ethiopia
}

Mebratu Asaye* and Tewodros Alemneh

Faculty of Veterinary Medicine, University of Gondar, Gondar-196, Ethiopia

\begin{abstract}
A cross-sectional study was carried out from October 2009 to March 2010 in and around Bahir Dar to determine the prevalence, identify the parasite species of lungworms in small ruminants by coprological and postmortem examinations, and to assess some of the determinant factors involved in the study area. Fecal and postmortem examinations were conducted in 534 (384 sheep and 150 goats) and 120 animals, respectively. An overall prevalence of $22.7 \%$ and $59.17 \%$ was observed by fecal and postmortem examinations, respectively. Dictyocaulus filaria was found the most prevalent species in the study area accounting $54.55 \%$ of the total positives. There was a significant difference $\left(X^{2}=4.296, p<0.05\right)$ in the prevalence of lungworms between species of animals. The highest prevalence was observed in goats $(28.7 \%)$ compared to the prevalence in sheep $(20.3 \%)$. The infection rate between male and female animals also showed significant difference $\left(x^{2}=17.645, p<0.05\right)$ with prevalence of $13.4 \%$ and $28.9 \%$, respectively. Regarding to age, the highest prevalence $(29.5 \%)$ was observed in young animals of less than a year of age while the lowest prevalence $(13.9 \%)$ observed in animals of above three years of age. The difference between the prevalence among the different age groups was statistically significant $\left(x^{2}=13.540, p<0.05\right)$. Different prevalence was observed between poor $(33.8 \%)$ and good $(19.1 \%)$ body conditioned animals, and the difference was statistically significant $\left(x^{2}=4.259, p<0.05\right)$. Highest infection prevalence was observed in November and the lowest in February; however, it did not follow the climatic changes of the year between months. Due to its impact on production, emphasis should be given for the control and prevention of lungworm infection in the study area.
\end{abstract}

Keywords: Dictyocaulus filarial; Muellerius capillaries; Protostrongylus rufescens; Prevalence; Lungworm; Small ruminants; Bahir Dar; Ethiopia

\section{Introduction}

In Ethiopia, livestock production contributes about $30-33 \%$ of agricultural gross domestic product (GDP) and more than $85 \%$ of the farm cash income mainly through meat, milk, eggs, wool, hides and skin $[1,2]$. Sheep and goats are the most numerous of man's domestic livestock. Of the world 1.614 million sheep and 475 million goats, $65 \%$ and $95 \%$ respectively; are located in developing countries $[3,4]$. As reported by ILRI, 2000; Ethiopia contributes 17 million small ruminants.

Small ruminants are especially important in the more extreme climates of the world. In Africa, they are noted for their ability to convent low opportunity cost feed in to high value products including meat, milk, fiber, manure and hides [3,4].

Small ruminants provide $33 \%$ of meat and $14 \%$ of milk consumption in Ethiopia [5]. In the central high lands where mixed crop-livestock production system is practiced, small ruminants account for $40 \%$ of cash income and $19 \%$ of the house hold meat consumption [6]. Yet these species have received much less attention from research and development agencies [7]. And the economic benefits to the farmers remain marginal due to prevailing disease, poor nutrition, poor animal production systems and general lack of veterinary care [8].

Helminthe parasites of ruminants are ubiquitous and prevalent with many tropical and sub-tropical environments of the world providing nearly perfect conditions for their survival and development. However, the clinical signs they cause in infected animals can be less obvious than signs of other livestock diseases. Partly for this reason, infections with gastro-intestinal and other helminthes parasites are among the most neglected areas of veterinary care in much of the developing world. It has however been established that high prevalence of the infection with less obvious sign associate with poor production and unthriftness [9].

Up to half of all sheep mortality and morbidity on farms in Ethiopian highlands are caused by pneumonia and endparasitism [7]. Endoparasites, including Dictyocaulus filaria, are major causes of death and morbidity [7]. Prevention and control of these parasites is, therefore, critical to enhance the economic benefit from these species of livestock. However, the incidence of parasitic diseases including respiratory helminthosis varies greatly from place to place depending on the relative importance of the factors [10]. Very few and limited studies were done so far pertaining to respiratory helminthes of small ruminants in and around Bahir Dar of Amhara National Regional state, North West of Ethiopia. Therefore, the objectives of this study were; to determine the prevalence of lungworm infection in small ruminants, to identify the species of the respiratory helminthes involved, and to identify some of the determinant factors involved, in and around Bahir Dar.

\section{Material and Methods}

\section{Study area}

The study was conducted in and around Bahir Dar. Bahir Dar is

${ }^{*}$ Corresponding author: Mebratu Asaye, Faculty of Veterinary Medicine University of Gondar, Gondar-196, Ethiopia, Tel: 0911262765; E-mail: assayemebratu@yahoo.com

Received June 11, 2015; Accepted June 29, 2015; Published July 01, 2015

Citation: Asaye M, Alemneh T (2015) Prevalence of Lungworm Infection of Smal Ruminants in and Around Bahir Dar City, Amhara Regional State, Ethiopia. J Veterinar Sci Technol S12: 002. doi:10.4172/2157-7579.S12-002

Copyright: ( 2015 Asaye M, et al. This is an open-access article distributed under the terms of the Creative Commons Attribution License, which permits unrestricted use, distribution, and reproduction in any medium, provided the original author and source are credited. 
located at $11^{\circ} 29^{\prime} \mathrm{N}$ latitude, $37^{\circ} 29^{\prime} \mathrm{E}$ longitude at about $570 \mathrm{~km}$ NorthWest of Addis Ababa. The area has middle altitude ranges from 15002300 meters above sea level which is called 'Woinadega'. The area receives a bimodal rainfall with an average annual rainfall ranging from 1200-1600 mm. The study area has mean annual temperature of $23^{\circ} \mathrm{C}$. The presence of the biggest lake and river in Ethiopia, Tana and Abay respectively, influences the climate of the study area. The land is covered by various bush formations, low woods mainly evergreen plants and some semi-humid and humid highland vegetation with major agricultural products like teff, wheat, sorghum, millet, maize and all pulse crops. Mixed crop-livestock production is the type of farming system in this area. According to the census made in 1996 by the Amhara National Regional state Agricultural Baerue (ANRSAB) there are 158,564 cattle, 18,827 sheep and goats, 8,000 equine and 366,666 poultry in Bahir Dar and its surroundings.

\section{Study population}

The study populations were sheep and goats in and around Bahir Dar town. Small ruminants in the study area are kept under extensive traditional management system. These animals are maintained in small house hold flocks of mixed age for subsistence and small scale private farms for sale. In the study area the number of goats is low compared to sheep population. Animals of less than one year of age form the largest proportion. Generally, the proportion of male to female is very small in any flock of sheep and goats.

\section{Study design}

A cross-sectional study design was carried out to determine the prevalence of small ruminant lungworm infection in and around Bahir Dar. A total of 534 small ruminants (384 sheep and 150 goats) obtained from each kebele of Bahir Dar and its surroundings were involved. The variable of interest considered as an output variable versus risk factors during the study was fecal status for larvae of lungworms and adult parasites in slaughtered animals. Age, sex, management conditions of the animals and seasons of the year were considered as explanatory variables.

\section{Sample size}

In this study the sample size required was determined based on sample size determination in random sampling for infinite population using expected prevalence of small ruminant lungworms at 5\% desired absolute precision according to Thrusfield [11]. Previous study on the prevalence of ovine lungworms in the study area revealed prevalence of $18.16 \%$ [12]. Therefore, using $18.16 \%$ expected prevalence and $5 \%$ absolute precision at $95 \%$ confidence level, the number of animals needed in this study to be 228. However; to increase the level of accuracy of determining the prevalence, the study sample size has been increased to 534 . A total of 120 small ruminants (105 sheep and 15 goats) were also examined at post mortem to see the presence of adult parasites.

\section{Sampling procedure}

Fecal samples $(n=534)$ were collected from small ruminants in the field and occasionally from animals coming to the veterinary clinic. Fecal samples were collected directly from the rectum of randomly selected animals using plastic gloves, put into a screw capped glass bottles (Universal bottles) and transported to Bahir Dar Regional Veterinary laboratory in the fresh state. While collecting fecal samples, the species of the animal, date of sampling, kebele, sex, age, management system, clinical signs of lungworm infection and the area were properly leveled. Sampled animals were categorized into three age groups as group $\mathrm{I} \leq 1$ year, group $\mathrm{II}=1-3$ years and group $\mathrm{III} \geq 3$ years of age. Age of study animals was determined based on owner's information, and dental estimation methods [13].

For post mortem examination, 120 lungs of animals slaughtered at Bahir Dar municipal abattoir were collected with simple random sampling.

\section{Identification and characterization}

In the laboratory following conventional methods of Baermann technique for identification of lungworm larvae, 25 gram of fresh feces was weighed from each sample for the extraction of $L_{1}$ larvae and enclosed in gauze fixed on to a string rode and submerged in a clean glass tube filled with fresh water. The whole apparatus was left for 24 hours and then the sediment was examined under the lower power of the microscope after siphoning off the supernatant. When positive, a drop of $1 \%$ iodine solution was used to immobilize the larvae for identification of species, otherwise it was registered negative for lungworm infection $[14,15]$.

Small ruminants slaughtered at Bahir Dar municipal abattoir and hotels were examined during the study period. Lungs from selected animals were palpated for the presence of protostrongylidea nodule. If the nodule present they were trimmed off and worms extracted from the tissue by gentile comprising a small non-calcified nodule or part of large nodule between two glass slides and then carefully testing the worm away from the tissue. Air passages were opened starting from the trachea to the small bronchi with fine blunt pointed scissors to detect the presence of adult dictyocaulidae $[16,17]$.

During identification of the larvae, the presence of $D$. filaria was confirmed by the finding of the first stage larvae with an anterior protoplasmic knob, and black granular intestinal inclusions in the faeces [18]. The larvae of $P$. rufescens and M. capillaris are differentiated by their characteristic feature at the tip of their tail $P$. rufescens has a wavy outline at the tip of its tail, but devoid of dorsal spine. On the other hand, $M$. capillaris has an undulating tip and a dorsal spine [19].

At necropsy, when tangled masses of worms mixed with frothy exudates are easily found in the trachea and bronchi, especially those of the diaphragmatic lobes [18] and are larger in size it is considered as D. filaria. If infected lungs contain red, grey or green pin head shaped nodules of 1 to $2 \mathrm{~mm}$ in diameter and located in the sub pleura of the diaphragmatic lobes found containing adult worms were dissected for $M$. capillaris [20]. If bronchioles were found closed with worms and exudates giving at electatic for infected lobules providing cone shaped granuloma like area of the affected lung tissue of varying size and color found containing active worms, was recorded positive for P. rufescens $[18,20]$.

\section{Data analysis}

Data were entered and managed in MS Excel work sheet. The analysis was conducted using SPSS 16.0. Prevalence of lungworm at animal was expressed as percentage with $95 \%$ confidence interval (CI) by dividing the total number of animals positive to lungworms to the total number of animals examined. An animal was considered positive for lungworms if it was positive either through fecal or postmortem examinations.

The significance of differences between the prevalence of lungworms was determined using Fisher's exact test when the numbers within the categories were too small for Chi-square test. Age, sex, 
Citation: Asaye M, Alemneh T (2015) Prevalence of Lungworm Infection of Small Ruminants in and Around Bahir Dar City, Amhara Regional State, Ethiopia. J Veterinar Sci Technol S12: 002. doi:10.4172/2157-7579.S12-002

Page 3 of 6

species and management system were considered as risk factors to see their association with the prevalence rate.

\section{Result}

\section{Prevalence of lungworm infection}

Coproscopic examination: Out of the total 534 fecal samples collected (384 sheep and 150 goats) and examined, 121 were positive for lungworms with overall prevalence of $22.7 \%$. The identified species of lungworms were D. filaria 66 (54.55\%), M. capillaris 41 (33.88\%), $P$. rufescens $3(2.48 \%)$ as well as mixed infections with D. filaria and $M$. capillaris $9(7.43 \%)$ and the three species $2(1.65 \%)$.

There was a significance difference on the prevalence of lungworm infection between sheep and goats $\left(\chi^{2}=4.296, \mathrm{p}<0.05\right)$. The prevalence was higher in goats (28.7\%) than sheep (20.3\%) (Table 1).

Among the 534 animals, the highest prevalence (29.5\%) was observed in young animals of less than one year of age while the lowest prevalence $(13.9 \%)$ was observed in animals of greater than three years. Similar prevalence is calculated in animals between these two age categories (Table 2). The difference between the prevalence was statistically significant $\left(\chi^{2}=13.540, \mathrm{p}<0.05\right)$ (Table 1$)$. Dictyocaulus filaria had the highest prevalence among the different age groups followed by Muellerius capillaris except in animals of greater than three years of age; in animals of greater than three years, M. capillaris contributes the highest prevalence. The difference between the prevalence of lungworm species among the different age groups was statistically significant $\left(\chi^{2}=11.430, p<0.05\right)$ (Table 2$)$.
An assessment was made on lungworm infection in relation to sex of small ruminants and accounted for a prevalence of $13.4 \%$ in males and $28.9 \%$ in females. There was statistically significance difference $\left(\chi^{2}=17.645, p<0.05\right)$ between male and female animals in susceptibility to lungworm infection (Table 1).

Study was conducted to see the influence of body condition on the prevalence of lungworm infection and revealed that there was statistically significant association $\left(\chi^{2}=4.259, \mathrm{p}<0.05\right)$ between the prevalence of lungworm and body condition of the animal with a prevalence of $19.1 \%$ and $33.8 \%$ in good and poor conditioned sheep and goats, respectively (Table 1 ).

To see the effect of management on the prevalence of lungworm infection, sheep and goats were categorized under extensive and semiintensive management systems. A prevalence of $23.98 \%$ was observed in animals kept under extensive management system while $7.14 \%$ in animals reared under semi-intensive system. The Difference between the prevalence was statistically significant (Fisher's exact $=0.011$, $\mathrm{p}<0.05)$ (Table 1).

The prevalence of lungworms was observed between the different months of the study period. The highest prevalence, $31.5 \%$ (5 of 16) and the lowest prevalence, $17.83 \%$ ( 28 of 157) was observed in November and February, respectively (Table 1).

\section{Postmortem examination}

120 (105 sheep and 15 goats) lung specimens of small ruminants slaughtered in Bahir municipal abattoir were observed through

\begin{tabular}{|c|c|c|c|c|c|}
\hline Variable & $\begin{array}{c}\text { Number of animals } \\
\text { Examined }\end{array}$ & $\begin{array}{c}\text { Number of animals } \\
\text { positive }\end{array}$ & Prevalence (\%) & Chi-square (x2) & P-Value \\
\hline \multicolumn{6}{|c|}{ Species } \\
\hline Sheep & 384 & 78 & 20.3 & 4.296 & $\mathrm{p}<0.05$ \\
\hline Goats & 150 & 43 & 28.7 & & \\
\hline \multicolumn{6}{|c|}{ Age (year) } \\
\hline$<1$ & 224 & 66 & 29.5 & & \\
\hline $1-3$ & 137 & 31 & 22.6 & 13.540 & $p<0.05$ \\
\hline$>3$ & 173 & 24 & 13.9 & & \\
\hline \multicolumn{6}{|c|}{ Sex of animals } \\
\hline Male & 216 & 29 & 13.4 & 17.645 & $p<0.05$ \\
\hline Female & 318 & 92 & 28.9 & & \\
\hline \multicolumn{6}{|c|}{ Body condition } \\
\hline Good & 404 & 77 & 19.1 & 4.259 & $p<0.05$ \\
\hline Poor & 130 & 44 & 33.8 & & \\
\hline \multicolumn{6}{|c|}{ Management system } \\
\hline November & 16 & 5 & 31.5 & & \\
\hline December & 156 & 36 & 23.08 & & \\
\hline January & 172 & 44 & 25.58 & & \\
\hline February & 157 & 28 & 17.83 & & \\
\hline March & 33 & 8 & 24.24 & & \\
\hline Total & 534 & 121 & 22.7 & & \\
\hline
\end{tabular}

Table 1: Prevalence of lungworm infection in small ruminants in relation to species, age, sex, body condition, management system, and months of the year.

\begin{tabular}{|c|c|c|c|c|c|}
\hline Age (year) & Df (\%) & Mc (\%) & Prf (\%) & Df Mc (\%) & Mixed \\
\hline$<1$ & $58(87.88)$ & $6(9.09)$ & 0 & $2(3.03)$ & $5(16.13$ \\
\hline $1-3$ & $5(16.13)$ & $17(54.84)$ & $2(6.45)$ & $2(6.45)$ \\
\hline$>3$ & $3(12.5)$ & $18(75.0)$ & $1(4.16)$ & $2(8.33)$ & 0 \\
\hline Total & $66(54.55)$ & $41(33.88)$ & $3(2.48)$ & $9(7.43)$ & $25(19.62)$ \\
\hline
\end{tabular}

Df: Dictyocaulus filaria, Mc: Muellerius capillaris, Prf: Protostrongylus rufescens.

Table 2: Species of lungworms identified and their prevalence among the three age groups. 
Citation: Asaye M, Alemneh T (2015) Prevalence of Lungworm Infection of Small Ruminants in and Around Bahir Dar City, Amhara Regional State, Ethiopia. J Veterinar Sci Technol S12: 002. doi:10.4172/2157-7579.S12-002

Page 4 of 6

\begin{tabular}{|c|c|c|c|c|}
\hline Adult lungworm species & D. filaria & M. capillaris & P. rufescens & Mixed \\
\hline $\begin{array}{c}\text { No of Positives Prevalence } \\
\text { (\%) }\end{array}$ & 23 & 31 & 17 & 0 \\
\cline { 2 - 5 } & 32.4 & 43.7 & 23.9 & 71 \\
\hline
\end{tabular}

Table 3: Prevalence of adult lungworms in small ruminants through postmortem examination.

postmortem examination for the presence of adult lungworms. Out of these, 71 (59.17\%) were positive for lungworm infection (Table 3).

\section{Discussion}

A cross-sectional study was conducted to determine the prevalence of lungworms in small ruminants. In this study, an overall prevalence of $22.7 \%$ was observed. Prevalence of $20.3 \%$ and $28.7 \%$ was recorded in sheep and goats, respectively. This level of prevalence is almost in agreement with previous study done by Mengestom $M$ in Tigray (Atsbi) (21.5\%) [21], Frewengel S in and around Mekele (13.24\%) [22], Muluken Y in and around Bahir Dar (18.16\%) [12] and Brook L at Assela (27.8\%) [23]. However, this result is not in agreement with the finding of Sissay A in the same area (44.7\%) [24], Tigist B in North and South Gondar Zones (39.6\%) [25], Alemu S in North East Ethiopia (53.6\%) [10], and Netsanet in Debrebirhan (73.25\%) [26].

The difference might be due to the difference in methods followed in the detection of the larvae and/or the study area which favors the survival of the larvae of the lungworms or it might be due to the nutritional status of the animals in the respective study areas which can influence level of immunity to be infested by lungworms. The topography of the area might also highly influence the prevalence by harboring the intermediate host.

In the current study, high prevalence of $(28.7 \%)$ was observed in goats compared to sheep $(20.3 \%)$ with significant difference $(\mathrm{p}<0.05)$. This result concedes with [10] who reported that goats were more susceptible to lungworm infection. This might be due to the difference in grazing behavior of these species of ruminants. Goats appear to be more susceptible to helminthes than sheep as they appear to develop less immunity. Sheep predominantly graze; pick up more parasites so have higher acquired resistance than goats which mostly consume browse. Goats with their browsing behavior consume uncontaminated matter with parasite larvae, so being less exposed to infective larvae, and therefore have lower acquired resistance than sheep [4].

On the attempt made to know the influence of sex on the overall prevalence of infection, the study clearly indicate that there is a significance difference $(\mathrm{p}<0.05)$ in susceptibility to lungworm infection in sheep and goats. Higher level of prevalence was observed in female (28.9\%) animals compared to the level of prevalence observed in male animals (13.4\%). This result contradicts with the earlier study of ref. [27] in Dessie and Kombolcha [26] in and around Debrebirhan who reported equal susceptibility to lungworm infection. However, it agrees with [10] and [24] who reported significant variation in the infection rate of lungworms in males and females. This difference in prevalence between female and male animals is probably due to the fact that resistance to infection is abrogated at the time of parturition and during early lactation. This preparturient relaxation of resistance results in the females' inability to expel adult worms which cause higher level of larval detection [28]. The way that males and females treated in terms of nutrition may also attribute for such differences. Males are kept for fattening to be sold later, except some which are kept for breeding, and receive more attention by small ruminant producers. Crop leftovers and remnants after human consumption, for instance, are provided primarily for males [10]
Regarding to age, generally, young sheep and goats were found more affected to lungworm infection. The highest prevalence (29.5\%) was observed in animals of less than a year followed by animals with 1-3 years of age (22.6\%), while the lowest prevalence (13.9\%) observed in animals of greater than three years and showed significant difference $(p<0.05)$. This is in agreement with refs. [12,25]. Accordingly, as the age of animals increase, susceptibility to lungworm infection decreases. This might be associated with the apparent inability of the host to develop acquired immunity so that young animals have the heaviest infection and the highest prevalence [15]. While in adult sheep and goats after primary infection, rapid solid immunity is developed and sheep and goats continually exposed to infection at low rate; therefore, the accusation of infection decrease [29].

In this study, the prevalence of lungworm species is found different among age groups. The finding of $D$. filaria as the most prevalent species $(54.55 \%)$ in the study area agrees with the previous report of Mengestom, Tigist, Paulos $[21,25,30]$. But this result is not in agreement with Muluken, Sissay and Frewengel in Addis Ababa who reported that $M$. capillaris was the most prevalent species $[12,22,24]$. The prevalence of $D$. filaria was highest in young animals of less than one year of age and decrease with increasing age of the animal, while M. capillaris was found to be highest in animals of greater than three years of age. This finding is in line with Alemu, Netsanet who reported higher prevalence of $D$. filaria in young animals than adults $[10,26]$. The prevalence of $P$. rufescens is the lowest of all species in small ruminants of all age groups. This result agrees with Muluken, Tigist [12,25].

The difference in the prevalence of D. filaria, and M. capillaris and $P$. rufescens infection in young's is associated with the difference in the lifecycles of these lung warms. D. filaria, which has a direct lifecycle, also takes less time to reach the infective stage and after ingestion, larvae can appear in the feces within five weeks [31]. Compared with $D$. filaria, transmission of $P$. rufescens and $M$. capillaris is epidemiologically a complex event involving host, parasite and intermediate host. Furthermore, development from first stage to infective stage larvae in the snail takes 12 to 14 days and the prepatent period of 30 to 60 days. The probability of infection, transmission and re-infection would therefore be much lower compared with $D$. filaria. These factors may explain why young animals have low rates of $P$. rufescens and $M$. capillaris infections [15]. The finding of $M$. capillaries infecting more older animals agree with the idea of long period of patency and the apparent inability of the final host to develop acquired immunity so that adult sheep and goats have heaviest infections and the highest prevalence [32].

The prevalence of lungworm infection on coprological examination was higher $(19.1 \%)$ in animals of poor body confirmation than those of well confirmed ones and the difference was statistically significant $(\mathrm{p}<0.05)$. This finding concedes with Alemu, Muluken, Mengestom $[10,12,21]$. The possible reason for this result might be associated with the nutritional management of animals. Poor body condition occurs as a result of lack of feed or nutritional management. This may lead to lack of resistance to infection and contribute for increased prevalence rate in poorly conditioned animals. Furthermore, considerable weight loss is associated with infection as a result of $D$. filaria [33]. 
In the present study the level of prevalence was compared between animals kept under extensive and semi-intensive management systems. The prevalence was higher $(23.98 \%)$ in small ruminants kept under extensive system of production, and the difference between the prevalence was statistically significant $(\mathrm{p}<0.05)$ which is in agreement with Alemu, Sissay, Tigist $[10,24,25]$. However, this was in different with the work of Muluken [12] in the same area. The possible reason for the current finding could be increased the degree of pasture contamination in extensive system of production may increase degree of exposure, so result in high prevalence [29]. In addition, the reason for this could partly be due to the fact that poorly nourished animals appeared to be less competent in getting ride of lungworm infection although it is not usual for well-fed animals to succumb to the disease provided the right environmental conditions are made available [20]. Furthermore, the response of the lung varies widely depending on the nutritional status, age of the host and the number of larvae ingested [14].

In this study, the monthly prevalence of lungworm infection within the study period was found higher (31.5\%) in November followed by January (25.58\%) while the lowest prevalence (17.83\%) was observed in February. This monthly dynamics of lungworms in small ruminants disagrees with the work of Alemu, Sissay who reported highest worm burden in November followed by December and then with a progressive decreasing and reaching to minimum during March [10,24]. This finding, however, is in agreement with Tigist [25]. The possible reason for the current finding might be associated with the difference in the areas and animals in which fecal samples were taken in each month of the study period.

In the current study, the prevalence of lungworm infection in sheep and goats obtained by coproscopic and postmortem examination was $22.7 \%$ and $59.17 \%$, respectively. This increased prevalence in postmortem examination agrees with the finding of Tigist in North and South Gondar, Muluken Y in the same area, Frewengel S in and around Mekele, and Eyobe E in Assella who reported higher prevalence in postmortem than coprological $[12,22,25,34]$. But the present finding differs from that of Sissay A in Bahir Dar and Paulos A in Arsi (Chilalo) who reported as higher prevalence in fecal than post mortem examination $[24,30]$.

One of the probable reasons attributed for such difference in the present finding could be related with worm nodes of protostrongylidae. In M. capillaris, those larvae which reach the lungs of sheep and goats remain in the parenchyma and become encysted in fibrous nodules. Because such nodules may not contain adults of both sexes, fertile eggs may not be deposited in air passage $[35,36]$. Due to this fact, the number of larvae in the faeces is often no indication of the degree of infestation [37]. In addition, the larvae of lungworms are found in 50-100 gm only in feces/ pellet of patent cases, otherwise, in the rest phase it may not be dispersed throughout the pellet [32]. This could also attribute to the probable outcome of negative result in coproscopic examination. The other reason might be animals on which coprological and postmortem examinations were not similar, so it might influence the fecal output of larvae of the parasite depending on their origin and examination timing. The stage of parasites also attributes for such differences. In the prepatent or postpatent phases or during hypobiosis, it is impossible to detect these parasites by fecal examination [14].

\section{Conclusion}

A cross-sectional study on lungworm infection in small ruminants in Bahir Dar by conducting fecal and postmortem examinations revealed overall prevalence of $22.7 \%$ and $59.17 \%$, respectively. Different risk factors were found affecting the prevalence. Of the two species, goats were found more susceptible to lungworm infestation. Female animals, young animals of less than one year of age, poorly conditioned animals, and those managed under extensive system of production were more prone to lungworm infection. The respiratory nematodes, D. filaria, M. capillaris and P. rufescens were the species of lungworms identified affecting small ruminants in the study area. D. filaria had the highest prevalence among the different age groups followed by $M$. capillaris except in animals of greater than three years of age, in which $M$. capillaris contributes the highest prevalence. Higher prevalence was observed by postmortem examination than the result obtained by coproscopic examination.

\section{Conflict of Interests}

The authors declare that there is no conflict of interests regarding the publication of this paper.

\section{Acknowledgements}

The authors are grateful to Bahir Dar Regional Veterinary Laboratory for provision of logistics, and University of Gondar, Faculty of Veterinary Medicine staffs for material and logistic supports, and their cooperation to bring this research to completion.

\section{References}

1. Befekadu K, Berhanu N (2000) Annual Report of the Ethiopian Economy. Addis Ababa. Ethiopian Economic Association 1199-2000.

2. ESPA (2003) Proceeding of the 10th annual conference of the Ethiopian society of animal production (ESAP) Addis Ababa, Ethiopia.

3. FAO (1986) Small ruminant production in the developing countries, In proceedings of an expert consultation held in Sofia, Bulgaria.

4. Wilsmore T (2006) Diseases of small ruminants in Ethiopia, the veterinary epidemiology and economics research unit school of agriculture's policy and development the University of Read, UK, pp. 67-72.

5. Asfaw W (1997) Country report, Ethiopia in proceeding of a seminar on livestock development policies in Eastern and Southern Africa.

6. Fletcher I, Zelalem A (1993) Ruminant productivity in Ethiopia mixed faming system. In: Preceding of the 4th national livestock improvement conference, IAR, Addis Ababa, Ethiopia.

7. International Livestock Research Institute (ILRI) (2000) Handbook of livestock statistical for developing countries socio-economic and policy research working paper 26. ILRI, Nairobi, Kenya. p. 299.

8. Sissay MM, Uggla A, Waller PJ (2007) Epidemiology and seasonal dynamics of gastrointestinal nematode infections of sheep in a semi-arid region of eastern Ethiopia. Vet Parasitol 143: 311-321.

9. Hansen J, Perry B (1994) the epidemiology, Diagnosis and control of helminth parasites of ruminants. ILRAD, Nairobi, Kenya pp.38.

10. Alemu S, Leykun EG, Ayelet G, Zeleke A (2006) Study on small ruminant lungworms in northeastern Ethiopia. Vet Parasitol 142: 330-335.

11. Thrusfield M (2005) Surveys in veterinary Epidemiology (2ndedn) Black well science Ltd, Cambridge, USA pp. 178-198.

12. Muluken $Y$ (2009) Prevalence of ovine lungworms in and around Bahir Dar. DVM Thesis. College of Agriculture and Veterinary Medicine, School of Veterinary Medicine, Jimma University, Jimma, Ethiopia.

13. Steele M (1996) Goats In: the tropical agriculturalist, London and basing stock MACULUAN education Itd, ACCT. pp. 79-83.

14. Fraserm CM (1991) The Merck veterinary manual, a hand book of diagnosis therapy and disease prevention and control for the veterinarians (7thedn) Merk and Co inc Rahway, Nit, USA, pp. 714-814.

15. Urquhart GM, Armour J, Duncan JL, Jennings FW (1994) Veterinary parasitology.

16. Kassai T (1999) Veterinary Helminthology. Butter worth helminthology Budapest, Hungary. 
Citation: Asaye M, Alemneh T (2015) Prevalence of Lungworm Infection of Small Ruminants in and Around Bahir Dar City, Amhara Regional State, Ethiopia. J Veterinar Sci Technol S12: 002. doi:10.4172/2157-7579.S12-002

17. Schneider T (2000) Helminthes of respiratory system In: veterinary medicine parasitology standing auflage. Parey bush vet log. Berlin 5: 193-198.

18. Dunn AM (1978) Veterinary Helminthology (2ndedn) William Heinemann Medical book LTD. London. pp. 203-204.

19. Geoffrey L (1962) Veterinary Helminthology and Entomology (5thedn) Oliver and Boyd.

20. Kimberling CV (1988) Jensen and Swift's Diseases of sheep (3rdedn) Philadelphia: Lea and Feigner. pp. 29-31.

21. Mengestom G (2008) Preliminary study on prevalence of ovine lungworm infection in Atsbi (Tigray), DVM Thesis, Jimma University, Jimma, Ethiopia.

22. Frewengel $S$ (1995) Prevalence of ovine dictyocaulosis in and around Mekele (Tigray), DVM Thesis, Addis Ababa University, Faculty of Veterinary Medicine, Debre Zeit, Ethiopia.

23. Brook L, Fesseha G, Shibru T (1986) The Seasonal occurrence of D. filaria (Rudolphi: 1890) in four selected sites of Ethiopia”: K. sci 9(1.2). pp. 25-38.

24. Sissay A (1996) Preliminary study on the prevalence of ovine lungworm infection in and around Bahir Dar", DVM Thesis, Addis Ababa University, Faculty of Veterinary Medicine, Debre Zeit, Ethiopia.

25. Tigist B (2009) Prevalence of lungworm Infection in small ruminants in North and South Gondar Zones" DVM Thesis, University of Gondar, Gondar, Ethiopia.

26. Netsanet B (1992) Study on the prevalence and control of lungworms (Dictyocaulus and Muellerius) in local Ethiopian highland sheep in and around Debrebirhan DVM Thesis, Addis Ababa University, Faculty of Veterinary Medicine, Debre Zeit, Ethiopia.

27. Teffera S (1993) Prevalence of ovine lungworms around Dessie and Kombolcha, DVM Thesis, Addis Ababa University, Faculty of Veterinary Medicine, Debre Zeit, Ethiopia.
28. Craig TM (1994) Epidemiology of internal parasite, effect of climate and host on reproductive cycle in parasite survival. In: small ruminants for the mixed animal practitioner, western veterinary conference, Las Vegas, Nevada.

29. Soulsby EJL (1982) Helminthes, arthropods and protozoa of domesticated animals (7thedn) Bailliere, Tindall, London. pp. 262-268.

30. Paulos A (2000) Importance and seasonal Dynamics of lungworm infections of small ruminants in Chillalo area, Arsi zone DVM Thesis, Addis Ababa University, Faculty of Veterinary Medicine, Debre Zeit, Ethiopia.

31. Soulsby EJL (1986) Helminthes, arthropods and protozoa of domesticated animals (8thedn) Bailliere, Tindall, London pp. 262-268.

32. Urquhart HM, Armour J, Duncan JL, Dunn AM, Jennings FW (1996) “Veterinary parasitology" (2ndedn) Black well science limited, London pp. 301-309, 1996.

33. Thomson RG (2008) Special Veterinary pathology, B.C Decker. Inc. Toronto Philadelphia pp. 112-113,

34. The prevalence of lungworm in ovine in Assela (2008) DVM Thesis, Jimma University, Jimma Ethiopia.

35. Radostits OM, Blood DC, Gay CC (1994)Veterinary Medicine, a text book of the disease of cattle, sheep, pigs, goats and horse (8thedn) Bailliere Tinda, London.

36. Blood DC, Radostits OM, Gay CC (1989) Veterinary Medicine: a text book of the disease of cattle, sheep, pigs, goats and horses, (7thedn) Balilliere Tindall pp. 1043-1044.

37. Radostit OM, Gay CC, Blood DC, Hinchclift KW (2007) Diseases associated with helminthes parasites. In: Veterinary Medicine, a text book of the disease of cattle, sheep, pigs, goats and horse (10thedn) Harcourt publishers limited, London pp. 1564-1569. 